\title{
Theoretical investigation of the degradation mechanisms in host and guest molecules used in OLED active layers
}

\author{
Paul Winget ${ }^{* a}$, Minki Hong ${ }^{\mathrm{a}}$, Jean-Luc Brédas ${ }^{\mathrm{a}, \mathrm{b}}$
}

${ }^{a}$ School of Chemistry and Biochemistry and Center for Organic Photonics and Electronics, Georgia Institute of Technology, Atlanta, Georgia 30332-0400; ${ }^{\mathrm{b}}$ Division of Physical Sciences and

Engineering, King Abdullah University of Science and Technology - KAUST, Thuwal 23955-6900, Kingdom of Saudi Arabia

\begin{abstract}
A feature of OLEDs that has to date received little attention is the prediction of the stability of the molecules involved in the electrical and optical processes. Here, we present computational results intended to aid in the development of stable systems. We identify degradation pathways and define new strategies to guide the synthesis of stable materials for OLED applications for both phosphorescent emitters and organic host materials. The chemical reactivity of these molecules in the active layers of the devices is further complicated by the fact that, during operation, they can be either oxidized or reduced (as they localize a hole or an electron) in addition to forming both singlet and triplet excitons.
\end{abstract}

Keywords: OLED, degradation mechanism, host, guest

\section{INTRODUCTION}

Though the first observation of organic electroluminescence occurred as early as the $1950 \mathrm{~s}^{1-4}$ and $1960 \mathrm{~s},{ }^{5}$ it was not until the demonstration by Tang and Van Slyke ${ }^{6}$ in 1987 of reasonably strong electroluminescence in diodes in which the active layers were composed of organic materials that organic light-emitting diodes (OLEDs) became a significant academic and industrial research interest. Today, OLED-based devices have entered the market of full-color displays and large-area solid-state lighting. Recent advances in efficiency coupled with low driving voltages and unprecedented picture quality have made these devices viable commercial products. Despite these successes, the lifetimes, particularly for deep blue emission, continue to be a limiting factor and cause for concern. ${ }^{7,8}$

In addition to extrinsic aging processes, e.g., the penetration of oxygen and water into the organic layers and subsequent (photo/electro)chemical reactions, there also exist degradation channels that result from intrinsic chemical reactions of the molecular materials used in the devices. ${ }^{9-11}$ Improved fabrication and encapsulation technologies have led to the conclusion that the limiting factor for device lifetime can be linked to the chemical structure of the molecules that comprise the device layers. It has been proposed that such intrinsic chemical reactions involving the organic molecules in the transport and emissive layers represent one of the main causes determining the loss in luminance efficiency ${ }^{12}$ and the lifetime of the device.

Despite the multitude of information on the luminescent properties of $\operatorname{Ir}(\mathrm{III})$-complexes, there have only been a few detailed investigations on deactivation pathways. Scheme 1 shows the canonical pathway for deactivation in these complexes. Singlet or triplet excitons formed from successive charge-transfer or energy-transfer events rapidly relax to the lowest state in the triplet manifold $\left(\mathrm{T}_{1}\right)$. Here, intersystem crossing occurs quickly as there is a large spin-orbit coupling (SOC) effect due to the presence of heavy atoms. For luminescent molecules, this emissive state has generally a metal-to-ligand charge-transfer $\left({ }^{3} \mathrm{MLCT}\right)$ character. This state can then emit a photon, or, if sufficient energy is available, undergo rearrangement to an alternate triplet state with ligand-to-ligand charge-transfer $\left({ }^{3} \mathrm{LLCT}\right)$, ligandcentered $\left({ }^{3} \mathrm{LC}\right)$, or metal-centered $\left({ }^{3} \mathrm{MC}\right)$ character. Direct photoexcitation of the $\operatorname{Ir}(\mathrm{III})$-complex leads to similar pathways. Depending on the nature of the cyclometalating and ancillary ligands, the relative energies of these states can vary considerably, resulting in different stabilities and device lifetimes.

Organic Light Emitting Materials and Devices XVIII, edited by Franky So, Proc. of SPIE Vol. 9183, 91830J

(C) 2014 SPIE · CCC code: 0277-786X/14/\$18 - doi: 10.1117/12.2062266 


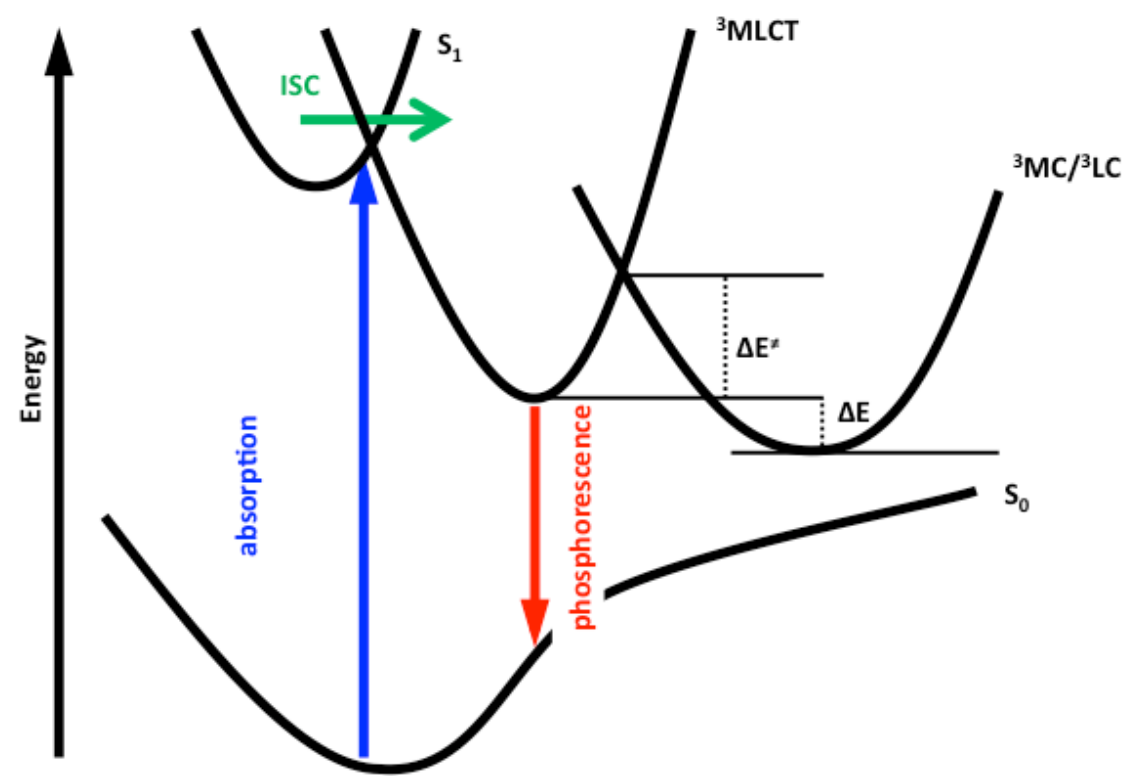

Figure 1. Canonical pathways for deactivation in $\operatorname{Ir}(\mathrm{III})$ complexes. Singlet or triplet excitons formed from successive charge-transfer or energy-transfer events rapidly relax to the lowest state in the triplet manifold $\left(\mathrm{T}_{1}\right)$, a ${ }^{3} \mathrm{MLCT}$ state. This emissive state can then emit a photon, or, if sufficient energy is available, undergo rearrangement to an alternate triplet state with ligand-to-ligand charge-transfer $\left({ }^{3} \mathrm{LLCT}\right)$, ligand-centered $\left({ }^{3} \mathrm{LC}\right)$, or metal-centered $\left({ }^{3} \mathrm{MC}\right)$ character.

As the phosphorescent materials are distributed within an appropriate organic semi-conductive host matrix to avoid selfquenching of phosphors, ${ }^{13-15}$ stability of the matrix molecules is also required. Previous attempts at understanding the lifetime of the host materials have focused on requiring a high-glass transition temperature $\left(T_{\mathrm{g}}\right)$, electrochemical stability, and morphological stability. ${ }^{15,16}$ The triplet energy $\left(\mathrm{E}_{\mathrm{T}}\right)$ of the host molecules must be higher than that of the emitter (dopant) to suppress energy back transfer. ${ }^{17}$ Thus, degradation problems are particularly acute in blue OLEDs as the energies involved in the molecular excitation processes are in the same range as the homolytic cleavage of single bonds between second and third-row atoms, on the order of $2-3 \mathrm{eV} .{ }^{18,19}$ The chemical reactivity of these molecules in the active layers of the devices is made even more complicated by the fact that, during operation, they can be either oxidized or reduced (as they localize a hole or an electron) in addition to forming both singlet and triplet excitons, as shown in Figure 2. It is important to note that estimation of the reaction rates from thermodynamic quantities is difficult since the reaction barriers for the various chemical processes on each of the potential energy surfaces for the ionic and excited states can be radically different, leading to different qualitative predictions even within an homologous series of host or guest molecules.

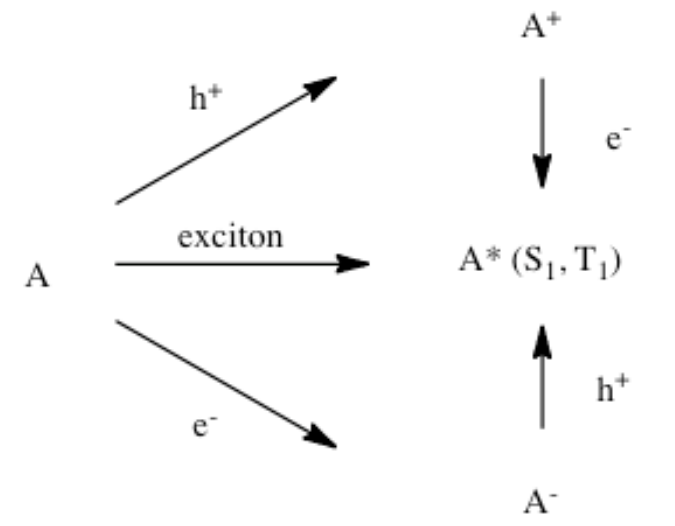

Figure 2. Possible routes for excited-state / ionized-state formation in an electrochemical device. 


\section{COMPUTATIONAL METHODOLGY}

\subsection{Computational Methods}

All the calculations were carried out at the quantum-mechanical level, using the density functional theory (DFT) $)^{20,21}$ methodology. Calculations were carried out with the Turbomole ${ }^{20-25}$ and Gaussian ${ }^{26}$ programs using the Becke gradient corrected exchange functiona ${ }^{27}$ in conjunction with the Lee Yang Parr correlation functional ${ }^{28}$ with three parameters, $\mathrm{B}^{2} \mathrm{LYP}^{29}$. We employed the split-valence SV(P) and 6-31G(d,p) $)^{30-32}$ basis sets for $\mathrm{H}, \mathrm{C}, \mathrm{N}, \mathrm{O}, \mathrm{Si}, \mathrm{S}$ and P. For iridium, the LANL2DZ electron core potential was used for $\operatorname{~Ir~}^{33}$ in conjunction with the LANL2DZ basis set. The ground-state $\left(\mathrm{S}_{0}\right)$ geometries were optimized via spin-restricted calculations while the optimal structures in the lowest triplet state $\left(\mathrm{T}_{1}\right)$ and radical-ion states were evaluated via spin-unrestricted calculations. The vertical and adiabatic ionization potential (VIP/IP) and electron affinity (VEA/EA) values were determined via the $\triangle$ SCF method based on the optimized geometries for the respective electronic states. The lowest vertical and adiabatic energies for singlet and triplet excitations were calculated using time-dependent (TD) DFT at the $\mathrm{S}_{0}$ and $\mathrm{T}_{1}$-state optimized structures. Calculations using different exchange correlation functionals, e.g. CAM-B3LYP/6-31G(d) and LC-B97X/6-31G(d) are also provided for these systems.

\section{DATA AND DISCUSSION}

\subsection{Degradation in Guest/Dopant Molecules}

Current theoretical studies for homoleptic phosphorescent $\operatorname{Ir}(\mathrm{III})$ emitters based on phenyl-pyridine $\left(\operatorname{Ir}(\mathrm{ppy})_{3}\right)$ and phenyl-pyrazole $\left(\operatorname{Ir}(\mathrm{ppz})_{3}\right)$, reported by Treboux et $a .^{34}$ on the basis of unrestricted DFT calculations, demonstrate a small barrier to the conversion process from the octahedral isomer to the open isomer (where the Ir-N bond is broken) in the triplet state. The prediction of such a ligand dissociation process is consistent with the findings from the combined theoretical and experimental studies of Sajoto et al. ${ }^{35}$ These authors also performed DFT calculations to show that the radiative ${ }^{3} \mathrm{MLCT}$ electronic state has only a $0.2 \mathrm{eV}$ barrier to the nonradiative metal-centered $\left({ }^{3} \mathrm{MC}\right)$ electronic state, which involves breaking of the Ir-N bond.

\subsection{Chemical Models}

We have carried out calculations on a series of facial-homoleptic compounds with ligands based on phenyl-pyridine (ppy), phenyl-pyrazole (ppz), phenyl-imidazole (pim) and a carbene complex (pmi). The octahedral and trigonalbipyramidal structures as well as the ligands are shown in Figure 3. Our first series of calculations indicated that these substitutions were able to manipulate the absorption and emission energies of these complexes. Based on the distribution of the HOMO and the LUMO, we show that the substitution pattern predicts the absorption and emission energies of these complexes. While this result has been shown in many previous reports, the energy of the metal-centered $\left({ }^{3} \mathrm{MC}\right)$ electronic state with a trigonal-bipyramidal structure can also be directly related to the substitutents on the ligand.
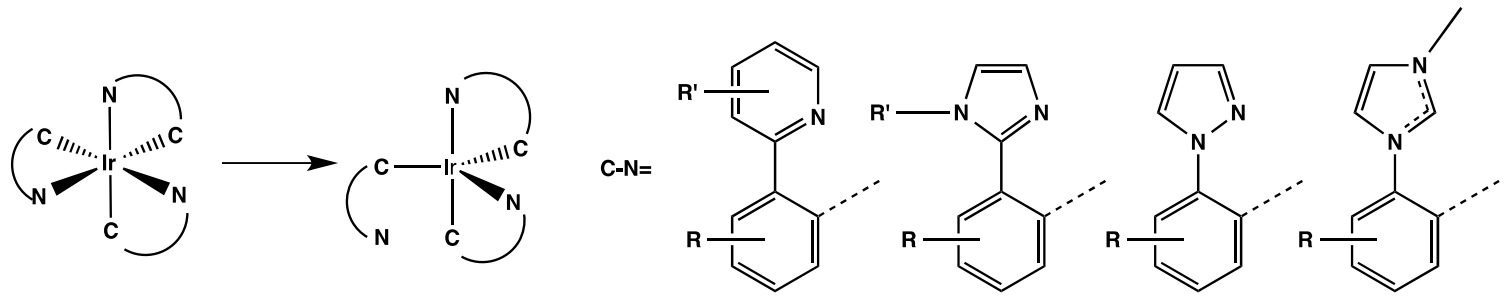

$R, \mathrm{R}^{\prime}=\mathrm{NO}_{2}, \mathrm{CN}, \mathrm{F}, \mathrm{CH}_{3}, \mathrm{CF}_{3}, \mathrm{OCH}_{3}, \mathrm{NCH}_{3}$

Figure 3. Molecular structures for the octahedral and trigonal-bipyramidal complexes as well as for the cyclometalating ligands and substituents.

In Figure 4, the energy required to dissociate the Ir-N bond, $\Delta \mathrm{E}$ in Figure 1, for each of the molecules studied is plotted as a function of the phosphorescence energy, i.e. the energy of the $\mathrm{T}_{1}->\mathrm{S}_{0} *$ transition. The values for $\operatorname{Ir}(\mathrm{ppy})_{3}$ and $\operatorname{Ir}(\mathrm{ppz})_{3}$ are similar to those of Treboux et al. ${ }^{34}$ and substituted $\operatorname{Ir}(\mathrm{ppy})_{3}$ and $\operatorname{Ir}(\mathrm{ppz})_{3}$ compounds from Sajoto et al. ${ }^{35}$. The ability of substituents to alter the energies of these molecules is shown in Figure 4 is a measure of the modification of the ligand-field strength. The general trend is apparent, with the increase in emission energy corresponding to a reduction in 
the energy needed to form the trigonal-bipyramidal structure, which in some cases is lower in energy than the octahedral structure. In order to understand the effects of the substituent on both the strength of the Ir-N bond and the ${ }^{3} \mathrm{MC}$ state, it is necessary to vary these two effects separately.

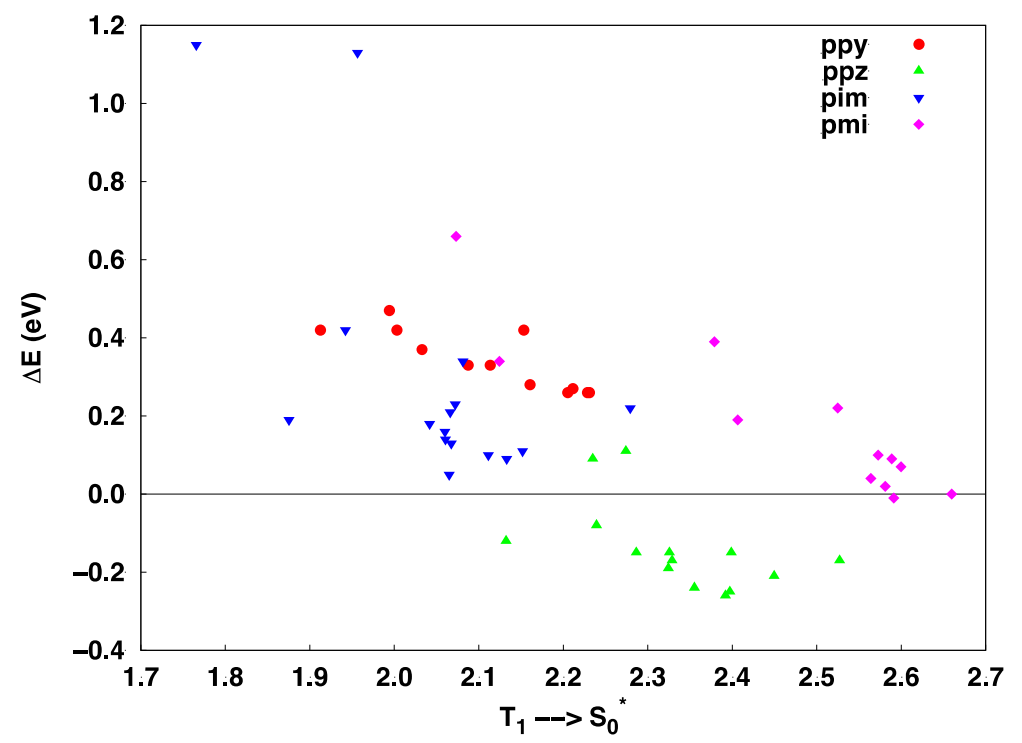

Figure 4. $\Delta \mathrm{E}$ (see Figure 1) for each of the molecules studied is plotted as a function of the phosphorescence energy for homoleptic Ir(III) complexes with ligands based on phenyl-pyridine (ppy), phenyl-pyrazole(ppz), phenyl-imidazole (pim) and a carbene complex (pmi).

In order to do this, we have also carried out calculations on a series of heteroleptic compounds combining some of the ligands from the homoleptic series. We began with phenyl-imidazole/phenyl-carbene complexes where the phenyl groups are in a facial arrangement. This minimizes the interactions of formally negatively charged carbon atoms with each other. Even with this simplification, there can be several unique trigonal-bipyramidal ( ${ }^{3} \mathrm{MC}$-type) structures, each of which has different thermodynamic properties. We find that the thermodynamic parameters for these complexes cannot be predicted from the corresponding homoleptic complexes.

\subsection{Degradation in Host Molecules}

Various materials based on a hole-transporting moiety and an electron-transporting moiety have been exploited as ambipolar host materials. Typically hole-transporting fragments based on carbazole ${ }^{13,36}$ or silane ${ }^{37,38}$ derivatives have been considered although issues related to device efficiency or lowering of device operating voltage remain. For example, the most commonly used carbazole-based material, 4,4'-bis( $N$-carbazolyl)-1,1'-biphenyl (CBP) with high triplet energy gaps and excellent hole transporting properties, has been widely used as host material for green and red phosphorescent emitters. ${ }^{39}$ However, high driving voltages were required in the devices due to its low electron drift mobility. More importantly, its triplet energy $\mathrm{E}_{\mathrm{T}}(2.55 \mathrm{eV})^{40}$ is too low for sky-blue phosphors such as FIrpic. ${ }^{41}$ Phosphine oxide (PO) $)^{15,16,42-49}$ and sulfone $\left(\mathrm{SO}_{2}\right)^{50,51}$ derivatives with high triplet energy have emerged as host materials for blue electrophosphorescence and have also been successfully utilized in OLEDs. For example, 4,4'bis(diphenylphosphine oxide) biphenyl (PO1), synthesized by Sapochak and co-workers, ${ }^{49}$ has a triplet exciton energy $(2.72 \mathrm{eV})$ higher than $\mathrm{CBP}$ through substitution of the carbazoles with diphenylphosphoryl $\left(\mathrm{Ph}_{2} \mathrm{P}=\mathrm{O}\right)$ groups; the reason is that the $\mathrm{P}=\mathrm{O}$ group prevents electronic communication between the central diphenyl core and the outer phenyl groups. Kippelen and co-workers ${ }^{51}$ have utilized 4,4'-bis(phenylsulfonyl) biphenyl (SO1) as an effective host material for blue OLEDs. As a result, the $\mathrm{PO}$ and $\mathrm{SO}_{2}$ functional groups have attracted great attention as functional groups for host materials. 
However, ambipolar host molecules based on these fragments have intrinsic weaknesses: phosphine oxides have weak C-P bonds, sulfones weak C-S bonds, and carbazoles weak C-N bonds, ${ }^{52}$ which can be easily broken in device operation. For example, facile decomposition of diphenyl sulfone (DPS) has been observed. ${ }^{53-57}$ DPS and related compounds decompose via homolytic cleavage of one of the two formally single bonds connecting the sulfur atom to an aromatic ring, a process which characterized by an activation energy of $8.5-8.8 \mathrm{kcal} / \mathrm{mol}^{57}$

\subsection{Chemical Models}

The structures of the molecules investigated are depicted in Fig. 5 and were chosen to include the impact of both paraand $m e t a$-substitutions of the aryl group as well as the impact of lowering the triplet energy through the incorporation of a biphenyl bridge.

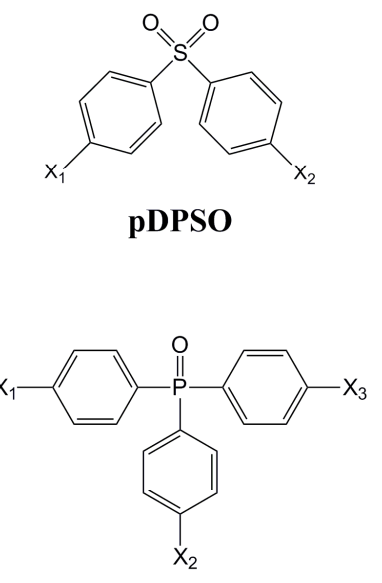

pTPPO

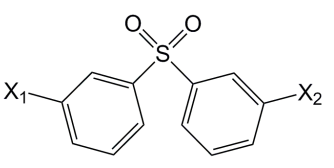

mDPSO

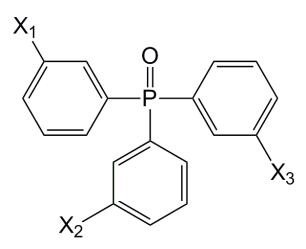

mTPPO

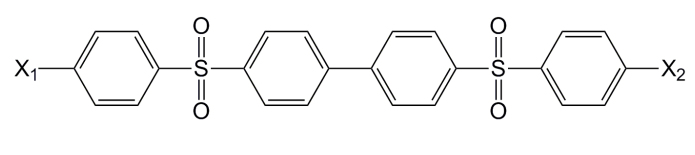

BPSO

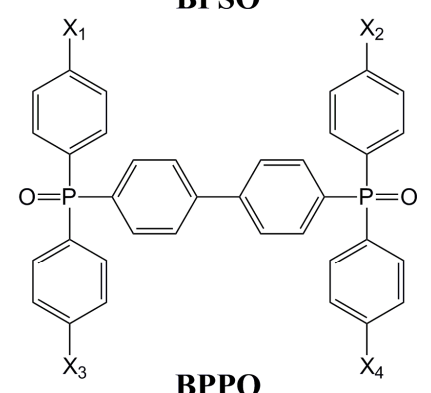

BPPO

$$
\begin{aligned}
& \text { 1: } X_{1}=X_{2}=X_{3}=X_{4}=H \\
& \text { 2: } X_{1}=X_{2}=X_{3}=X_{4}=N_{2} \\
& \text { 3: } X_{1}=C B Z, X_{2}=X_{3}=H \\
& \text { 4: } X_{1}=X_{2}=C B Z, X_{3}=X_{4}=H \\
& \text { 5: } X_{1}=X_{2}=X_{3}=X_{4}=C B Z \\
& \text { 6: } X_{1}=X_{2}=X_{3}=X_{4}=\text { triCBZ }
\end{aligned}
$$

\section{$\mathrm{CBZ}=\mathrm{N}$-carbazolyl}

triCBZ=N-3,6-bis(di-9H-carbazol-9-yl) carbazolyl

Figure 5. Prototypical host materials studied.

We find that the dissociation energy for the sulfones, i.e. the energy needed to break the sulfur aromatic carbon bond, is consistent across all the substitutions, ranging between 2.9 to $3.0 \mathrm{eV}$. Similarly, the dissociation energy for the phosphine oxide - carbon bond is 3.5 to $3.6 \mathrm{eV}$. Figure 6 shows the transition-state energy and the overall dissociation energy as a function of the adiabatic triplet energy. It is remarkable that, regardless of the energy of the triplet state $T_{1}$ in these compounds, the energy of the transition state relative to $\mathrm{S}_{0}$ is constant. Thus, the ability to alter the transition state energies of these molecules can be controlled through the building blocks in ambipolar materials, but there is only limited effect from the electron-donating substituents on these building blocks. 


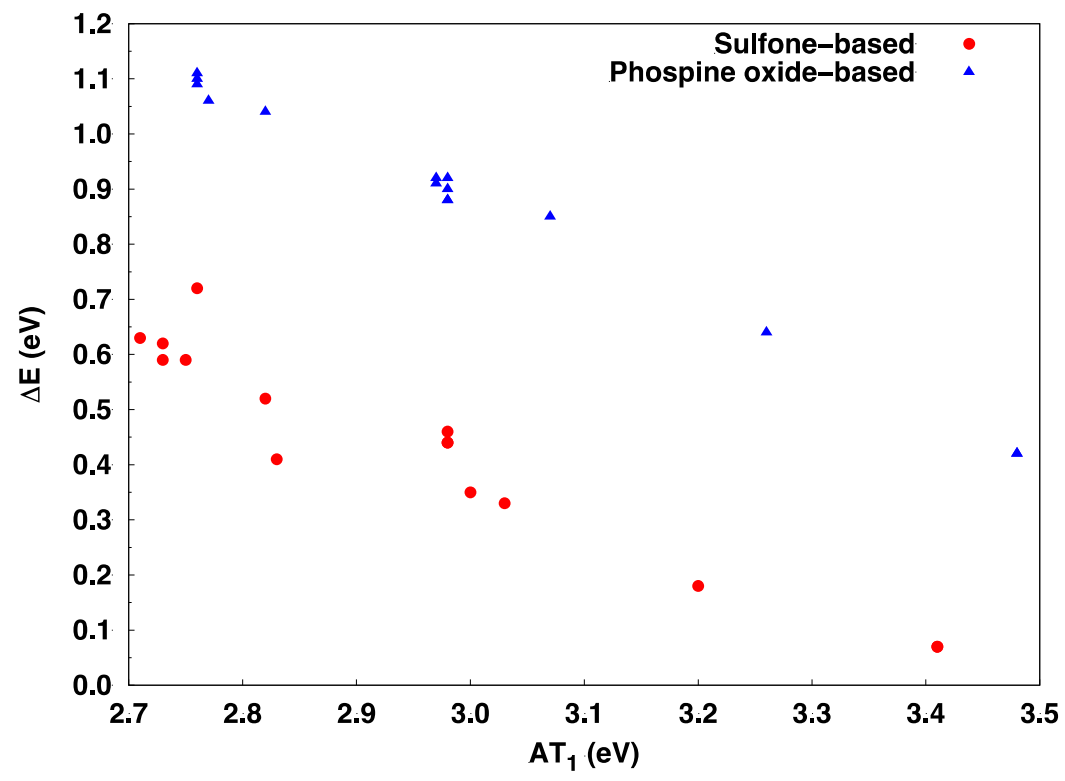

Figure 6. Transition-state energy as a function of the adiabatic triplet energy for a series of phosphine oxide- (PO) and sulfone- (SO) based host materials.

\section{CONCLUSIONS}

While improvements in purification, processing, and encapsulation methods can prevent extrinsic degradation processes, they do not preclude molecular-level intrinsic decomposition processes. Therefore, solutions leading to longer lifetimes must come from improvements in the molecular materials themselves. In order to engineer molecular components possessing high figures of merit in terms of both device performance and lifetime, it is required to gain fundamental knowledge of the degradation pathways. Here, we addressed from a computational standpoint the molecular factors which effect the formation of a non-radiative iridium(III) structure with a trigonal-bipyramidal structure. We have also presented data on prototypical host materials confirming that increasing the triplet energy for blue emission directly leads to a decrease in the stability of the materials.

\section{ACKNOWLEDGEMENTS}

This work was supported by the SAMSUNG Global Research Outreach (GRO) Program. The computations reported here were performed at the Georgia Tech Center for Computational Molecular Science and Technology, funded through a NSF CRIF award (Grant No. CHE0946869) and by the Georgia Institute of Technology. We thank Drs. ChangHo Noh Huifang Li, and Chad Risko for helpful discussions.

\section{REFERENCES}

[1] Bernanose, A., Comte, M., and Vouaux, P., "Sur un nouveau mode d'emission lumineuse chez certains composes organiques," J. Chim. Phys. Phys.-Chim. Biol., 50(1), 64-68 (1953).

[2] Bernanose, A., and Marquet, G., "Electroluminescence du carbazol par les champs electriques alternatifs aracteriszation de l'electrophotoluminescence organique," J. Chim. Phys. Phys.-Chim. Biol., 51(5), 255-259 (1954). 
[3] Bernanose, A., and Michon, F., "Electroluminescence organique et phosphorescence," J. Chim. Phys. Phys.Chim. Biol., 51(10), 622-623 (1954).

[4] Bernanose, A., and Vouaux, P., "Electroluminescence organique: etude du mode d'emission," J. Chim. Phys. Phys.-Chim. Biol., 50(4), 261-\& (1953).

[5] Pope, M., Kallmann, H.P., and Magnante, P., "Electroluminescence in Organic Crystals,” J. Chem. Phys., 38, 2042-2043 (1963).

[6] Tang, C.W., and Vanslyke, S.A., "Organic electroluminescent diodes," Appl. Phys. Lett., 51(12), 913-915 (1987).

[7] Sivasubramaniam, V., Brodkorb, F., Hanning, S., Buttler, O., Loebl, H.P., Elsbergen, V.V., Boerner, H., Scherf, U., and Kreyenschmidt, M., "Degradation of HTL layers during device operation in PhOLEDs," Solid State Sci., 11, 1933-1940 (2009).

[8] Sivasubramaniam, V., Brodkorb, F., Hanning, S., Loebl, H.P., Van Elsbergen, V., Boerner, H., Scherf, U., and Kreyenschmidt, M., "Investigation of FIrpic in PhOLEDs via LC/MS technique," Cent. Eur. J. Chem., 7, 836845 (2009).

[9] Scholz, S., Meerheim, R., Walzer, K., and Leo, K., "Chemical degradation mechanisms of organic semiconductor devices," Proc. SPIE, 6999, 1B-(1-10) (2008).

[10] Kondakov, D.Y., "Role of chemical reactions of arylamine hole transport materials in operational degradation of organic light-emitting diodes," J. Appl. Phys., 104(8), 084520-9 (2008).

[11] Kondakov, D.Y., Brown, C.T., Pawlik, T.D., and Jarikov, V.V., "Chemical reactivity of aromatic hydrocarbons and operational degradation of organic light-emitting diodes," J. Appl. Phys., 107(2), 024507-8 (2010).

[12] Kondakov, D.Y., Lenhart, W.C., and Nichols, W.F., "Operational degradation of organic light-emitting diodes: Mechanism and identification of chemical products," J. Appl. Phys., 101(2), 024512-7 (2007).

[13] Tsai, M.H., Hong, Y.H., Chang, C.H., Su, H.C., Wu, C.C., Matoliukstyte, A., Simokaitiene, J., Grigalevicius, S., Grazulevicius, J.V., and Hsu, C.P., "3-(9-Carbazolyl)carbazoles and 3,6-Di(9-carbazolyl)carbazoles as Effective Host Materials for Efficient Blue Organic Electrophosphorescence," Adv. Mater., 19(6), 862-866 (2007).

[14] Padmaperuma, A.B., Sapochak, L.S., and Burrows, P.E., "New Charge Transporting Host Material for Short Wavelength Organic Electrophosphorescence: 2,7-Bis(diphenylphosphine oxide)-9,9-dimethylfluorene," Chem. Mater., 18(9), 2389-2396 (2006).

[15] Chou, H.-H., and Cheng, C.-H., "A Highly Efficient Universal Bipolar Host for Blue, Green, and Red Phosphorescent OLEDs," Adv. Mater., 22(22), 2468-2471 (2010).

[16] Jeon, S.O., and Lee, J.Y., "Phosphine oxide derivatives for organic light emitting diodes," J. Mater. Chem., 22(10), 4233-4243 (2012).

[17] Sapochak, L.S., Padmaperuma, A.B., Cai, X., Male, J.L., and Burrows, P.E., "Inductive effects of diphenylphosphoryl moieties on carbazole host materials: Design rules for blue electrophosphorescent organic light-emitting devices,” J. Phys. Chem. C, 112(21), 7989-7996 (2008).

[18] Blanksby, S.J., and Ellison, G.B., "Bond Dissociation Energies of Organic Molecules," Acc. Chem. Res., 36(4), 255-263 (2003).

[19] Luo, Y.-R., [Handbook of Bond Dissociation Energies in Organic Compounds] CRC Press, Boca Raton, FL(2003).

[20] Treutler, O., and Ahlrichs, R., "Efficient Molecular Numerical Integration Schemes,” J. Chem. Phys., 102, 346 (1995).

[21] V. Arnim, M., and Ahlrichs, R., "Performance of parallel TURBOMOLE for Density Functional Calculations," J. Comp. Chem., 19, 1746 (1998).

[22] Turbomole v. 6.1 University of Karlsruhe and Forschungszentrum Karlsruhe GmbH, Karlsruhe (2009).

[23] Ahlrichs, R., Bär, M., Häser, M., Horn, H., and Kölmel, C., "Electronic Structure Calculations on Workstation Computers: The Program System TURBOMOLE.," Chem. Phys. Lett., 162(3), 165 (1989).

[24] Bauernschmitt, R., and Ahlrichs, R., "Treatment of Electronic Excitations within the Adiabatic Approximation of Time Dependent Density Functional Theory.," Chem. Phys. Lett., 256, 454 (1996).

[25] Furche, F., and Ahlrichs, R., "Adiabatic time-dependent density functional methods for excited state properties,” J. Chem. Phys., 121, 12772 (2004).

[26] Gaussian 09 Gaussian Inc., Wallingford CT (2009).

[27] Becke, A.D., "Density-Functional Exchange-Energy Approximation with Correct Asymptotic-Behavior," Phys. Rev. A, 38(6), 3098-3100 (1988). 
[28] Lee, C., Yang, W., and Parr, R.G., "Development of the Colle-Salvetti Correlation-Energy Formula into a Functional of the Electron Density," Phys. Rev. B, 37, 785 (1988).

[29] Becke, A.D., "Density-functional thermochemistry. IV. A new dynamical correlation functional and implications for exact-exchange mixing," J. Chem. Phys., 104, 1040-1046 (1996).

[30] Ditchfield, R., Hehre, W.J., and Pople, J.A., "Self-Consistent Molecular Orbital Methods. 9. Extended Gaussian-Type Basis for Molecular Orbital Studies of Organic Molecules," J. Chem. Phys., 54, 724-728 (1971).

[36] Chen, Y.-C., Huang, G.-S., Hsiao, C.-C., and Chen, S.-A., "High Triplet Energy Polymer as Host for Electrophosphorescence with High Efficiency," J. Am. Chem. Soc., 128(26), 8549-8558 (2006).

[37] Lin, J.-J., Liao, W.-S., Huang, H.-J., Wu, F.-I., and Cheng, C.-H., "A Highly Efficient Host/Dopant Combination for Blue Organic Electrophosphorescence Devices," Adv. Funct. Matl., 18(3), 485-491 (2008).

[38] Lyu, Y.-Y., Kwak, J., Kwon, O., Lee, S.-H., Kim, D., Lee, C., and Char, K., "Silicon-Cored Anthracene Derivatives as Host Materials for Highly Efficient Blue Organic Light-Emitting Devices," Adv. Mater., 20(14), 2720-2729 (2008).

[39] Adachi, C., Kwong, R.C., Djurovich, P., Adamovich, V., Baldo, M.A., Thompson, M.E., and Forrest, S.R., "Endothermic energy transfer: A mechanism for generating very efficient high-energy phosphorescent emission in organic materials," Appl. Phys. Lett., 79(13), 2082-2084 (2001).

[40] Tokito, S., Iijima, T., Tsuzuki, T., and Sato, F., "High-efficiency white phosphorescent organic light-emitting devices with greenish-blue and red-emitting layers," Appl. Phys. Lett., 83(12), 2459-2461 (2003).

[41] You, Y., and Park, S.Y., "Inter-Ligand Energy Transfer and Related Emission Change in the Cyclometalated Heteroleptic Iridium Complex: Facile and Efficient Color Tuning over the Whole Visible Range by the Ancillary Ligand Structure,” J. Am. Chem. Soc, 127(36), 12438-12439 (2005).

[42] Polikarpov, E., Swensen, J.S., Chopra, N., So, F., and Padmaperuma, A.B., "An ambipolar phosphine oxidebased host for high power efficiency blue phosphorescent organic light emitting devices," Appl. Phys. Lett., 94(22), - (2009).

[43] Ding, J., Wang, Q., Zhao, L., Ma, D., Wang, L., Jing, X., and Wang, F., “Design of star-shaped molecular architectures based on carbazole and phosphine oxide moieties: towards amorphous bipolar hosts with high triplet energy for efficient blue electrophosphorescent devices," J. Mater. Chem., 20(37), 8126-8133 (2010).

[44] Burrows, P.E., Padmaperuma, A.B., Sapochak, L.S., Djurovich, P., and Thompson, M.E., "Ultraviolet electroluminescence and blue-green phosphorescence using an organic diphosphine oxide charge transporting layer," Appl. Phys. Lett., 88(18), - (2006).

[45] Chang, H.-H., Tsai, W.-S., Chang, C.-P., Chen, N.-P., Wong, K.-T., Hung, W.-Y., and Chen, S.-W., "A new tricarbazole phosphine oxide bipolar host for efficient single-layer blue PhOLED," Org. Electron., 12(12), 2025-2032 (2011).

[46] Cai, X., Padmaperuma, A.B., Sapochak, L.S., Vecchi, P.A., and Burrows, P.E., "Electron and hole transport in a wide bandgap organic phosphine oxide for blue electrophosphorescence," Appl. Phys. Lett., 92(8), - (2008).

[47] Shao, S., Ding, J., Ye, T., Xie, Z., Wang, L., Jing, X., and Wang, F., “A Novel, Bipolar Polymeric Host for Highly Efficient Blue Electrophosphorescence: a Non-Conjugated Poly(aryl ether) Containing Triphenylphosphine Oxide Units in the Electron-Transporting Main Chain and Carbazole Units in HoleTransporting Side Chains," Adv. Mater., 23(31), 3570-3574 (2011).

[48] Jeon, S.O., Yook, K.S., Joo, C.W., and Lee, J.Y., "Phenylcarbazole-Based Phosphine Oxide Host Materials For High Efficiency In Deep Blue Phosphorescent Organic Light-Emitting Diodes," Adv. Funct. Matl., 19(22), 3644-3649 (2009). 
[49] Sapochak, L.S., Padmaperuma, A.B., Vecchi, P.A., Qiao, H., and Burrows, P.E., "Design strategies for achieving high triplet energy electron transporting host materials for blue electrophosphorescence." 6333, 63330F-63330F-13.

[50] Hsu, F.-M., Chien, C.-H., Hsieh, Y.-J., Wu, C.-H., Shu, C.-F., Liu, S.-W., and Chen, C.-T., "Highly efficient red electrophosphorescent device incorporating a bipolar triphenylamine/bisphenylsulfonyl-substituted fluorene hybrid as the host," J. Mater. Chem., 19(42), 8002-8008 (2009).

[51] Kim, S.-J., Leroy, J., Zuniga, C., Zhang, Y., Zhu, L., Sears, J.S., Barlow, S., Brédas, J.-L., Marder, S.R., and Kippelen, B., "High-efficiency blue-green electrophosphorescent light-emitting devices using a bis-sulfone as host in the emitting layer," Org. Electron., 12, 1314-1318 (2011).

[52] Lin, N., Qiao, J., Duan, L., Li, H., Wang, L., and Qiu, Y., “Achilles Heels of Phosphine Oxide Materials for OLEDs: Chemical Stability and Degradation Mechanism of a Bipolar Phosphine Oxide/Carbazole Hybrid Host Material,” J. Phys. Chem. C, 116(36), 19451-19457 (2012).

[53] Chen, X., Gao, L., Fang, W., and Phillips, D.L., "Theoretical Insight into the Photodegradation of a Disulfide Bridged Cyclic Tetrapeptide in Solution and Subsequent Fast Unfolding-Refolding Events," J. Phys. Chem. B, 114(15), 5206-5214 (2010).

[54] Caselli, M., Ponterini, G., and Vignali, M., "Irradiation-wavelength dependent photochemistry of the bichromophoric sulfonylurea chlorsulfuron," Journal of Photochemistry and Photobiology A: Chemistry, 138(2), 129-137 (2001).

[55] Abdul-Rasoul, F., Catherall, C.L.R., Hargreaves, J.S., Mellor, J.M., and Phillips, D., "Photodecomposition of commercial polysulphones and model diaryl sulphones," Eur. Polym. J., 13(12), 1019-1023 (1977).

[56] Mackle, H., "The thermochemistry of sulphur-containing molecules and radicals-II : The dissociation energies of bonds involving sulphur: the heats of formation of sulphur-containing radicals," Tetrahedron, 19(7), 11591170 (1963).

[57] Ponterini, G., and Momicchioli, F., "Photophysics and photochemistry of diphenylsulfone. 1. The triplet mechanism of photodissociation," J. Phys. Chem., 92(14), 4084-4088 (1988). 